\title{
Yürürken Telefon Kullanımı Yürümenin Spatio-temporal Karakteristiklerini Etkiler mi?
}

\author{
Ayşe Ünal ${ }^{1 *}$, Gülsüm T1kaç², Filiz Altuğ $\breve{g}^{3}$ \\ ${ }^{1 *}$ Pamukkale Üniversitesi, Fizik Tedavi ve Rehabilitasyon Yüksekokulu, Nörolojik Rehabilitasyon Anabilim Dalı, Denizli, Türkiye, (ORCID: 0000-0003-0959-5664), \\ aunal@pau.edu.tr,pt.aunal@gmail.com \\ ${ }^{2}$ Pamukkale Üniversitesi, Fizik Tedavi ve Rehabilitasyon Yüksekokulu, Nörolojik Rehabilitasyon Anabilim Dalı, Denizli, Türkiye, (ORCID: 0000-0001-7375-6747), \\ gtikac@pau.edu.tr \\ ${ }^{3}$ Pamukkale Üniversitesi, Fizik Tedavi ve Rehabilitasyon Yüksekokulu, Nörolojik Rehabilitasyon Anabilim Dalı, Denizli, Türkiye, (ORCID: 0000-0002-4287-8562), \\ fkural@pau.edu.tr
}

(International Conference on Design, Research and Development (RDCONF) 2021 - 15-18 December 2021)

(DOI: $10.31590 /$ ejosat.1040001)

ATIF/REFERENCE: Ünal, A., Tıkaç, G. \& Altuğ, F. (2021). Yürürken Akıllı Telefon Kullanımı Yürümenin Spatio-temporal Karakteristiklerini Etkiler mi? Avrupa Bilim ve Teknoloji Dergisi, (32), 362-366.

$\ddot{O} \mathbf{z}$

Telefon kullanımı günlük hayatımızın vazgeçilmez bir parçası olup, bize pek çok alanda kolaylık sağlamaktadır. Ancak, alışkanlık yapması nedeniyle pek çok olumsuzluğu da beraberinde getirmektedir. Gün içinde pek çok işi yaparken telefon kullanımının devam etmesi yapılan işe odaklanmayı zorlaştırmaktadır. Bu durum, kaza veya yaralanmalarla sonuçlanabilmektedir. Bu çalışmanın amacı, yürürken telefon kullanımının yürümenin spatio-temporal karakteristikleri üzerindeki etkisini araştırmaktır. Çalışmaya 20-30 yaş arası

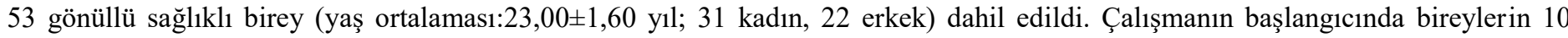
metrelik mesafeyi kendi yürüme hızlarında yürümesi istendi. Daha sonra 10 metrelik mesafeyi sirasıyla cep telefonunda müzik dinleyerek, metin yazarak, sosyal medyada dolaşarak ve oyun oynayarak tamamlaması istendi. Bütün bu aktiviteler sırasında bireylerin yürüme karakteristikleri BTS G-Walk Yürüme Analiz Sistemi kullanılarak yürüme hızı, kadans, adım uzunluğu, çift adım uzunluğu, duruş fazı, sallanma fazı, yürüme kalitesi ve pelvis simetrisi kaydedilmiştir. Yürüme sırasında cep telefonu kullanımı nedeniyle yürüyüşün hızı, kadansı, çift adım uzunluğu, duruş fazı, sallanma fazı ve pelvik rotasyon simetrisinde belirgin bozukluklar görülmüştür $(\mathrm{p}<0.05)$. Telefonların, yürürken kullanımı normal yürüyüş periyodunda anormal değişikliklere sebep olmakta ve yürüyüş simetrisini bozmaktadır.

Anahtar Kelimeler: Sağlıklı gönüllü, Cep telefonu, Yürüme analizi.

\section{Does Telephone Use While Walking Affect Spatio-temporal Characteristics of Gait?}

\begin{abstract}
Telephone use is an indispensable part of our daily life and provides us convenience in many areas. However, it brings with it many negativities due to its habit-forming. Continuing to use the phone while doing many things during the day makes it difficult to focus on the work being done. This may result in an accident or injury. The aim of this study is to investigate the effect of phone use while walking on the spatio-temporal characteristics of gait. Fifty-three healthy volunteers aged 20-30 years (mean age: $23.00 \pm 1.60$ years; 31 females, 22 males) were included in the study. At the beginning of the study, individuals were asked to walk 10 meters at their own walking speed. Afterwards, they were asked to complete the 10-meter distance by listening to music on the cell phone, texting, surfing social media and playing games, respectively. During all these activities, the gait characteristics of individuals were recorded using the BTS G-Walk Gait Analysis System, such as gait speed, cadence, step length, stride length, stance phase, swing phase, gait quality and pelvic symmetry. Significant disturbances in gait speed, cadence, stride length, stance phase, swing phase and symmetry of pelvic rotation were observed due to cell phone use during walking $(\mathrm{p}<0.05)$. The use of phones while walking causes abnormal changes in the normal walking period and disrupts the gait symmetry.
\end{abstract}

Keywords: Healthy volunteer, Cell phone, Gait analysis.

\footnotetext{
*Sorumlu Yazar: aunal@pau.edu.tr,pt.aunal@gmail.com
} 


\section{Giriş}

Teknolojinin gelişmesi iletişim alanındaki yenilikleri de beraberinde getirmiştir. İletişim alanındaki gelişmeler ise cep telefonu kullanımın tüm toplumlarda artmasıyla sonuçlanmıştır. Her geçen gün artan cep telefonu kullanımı toplumun hemen her kesiminde en fazla tercih edilen iletişim araçlarından olmuştur (Oliver \& Goerke, 2007; Yang vd. 2021).

Günümüzde sadece iletişim amacıyla değil; aynı zamanda eğlence, bilgi edinme gibi pek çok amaçla kullanılan cep telefonları günlük hayatı oldukça kolaylaştıran bir araç haline gelmiştir. Her ne kadar günlük hayatta kullanım kolaylığı sağlayarak yaşantımızı kolaylaştırsa da uzun süre veya uygun olmayan koşullarda kullanımında sağlı̆̆ımızı olumsuz yönde etkilediği de yapılan çalışmalarda gösterilmiştir (Yen vd., 2009).

Son yıllarda özellikle gençler zamanlarının çoğunu cep telefonu kullanmaya harcamaktadır. Uzun süreli cep telefonu kullanımının baş ağrısından, kas-iskelet sistemi problemlerine kadar pek çok soruna sebep olduğu bildirilmiştir. Bununda birlikte uyku problemleri, dikkat eksikliği ve konsantrasyon problemlerine de yol açtığ çalışmalarda gösterilmiştir (Mustafaoglu vd., 2021; Yen vd., 2009).

Özellikle gençler tarafından gün içinde yapacakları çoğu işi telefon aracılığıyla tamamlamaya çalıştıkları, çoğunlukla da bu işleri yaparken aynı zamanda telefon kullanımını sürdürdükleri görülmektedir (Crowley, Madeleine, \& Vuillerme, 2019). Yapılan bir çalışmada 31 yaş altındaki yayaların trafikte yaptıkları kazalarının çoğunluğu cep telefonu kullanımıyla ilişkilendirilmiştir. Telefon kullanarak yürüme ve karşıdan karşıya geçme sırasında azalmış dikkat, çevreye karşı farkındalığın azalması nedeniyle yayalardan kaynaklanan kazaların giderek arttığı belirtilmiştir (Nasar \& Troyer, 2013).

Çalışmamızın amacı yürürken telefon kullanımın yürümenin spatio-temporal karakteristikleri üzerine etkisini araştırmaktır.

\section{Materyal ve Metot}

\subsection{Katılımcılar}

Çalışma, Pamukkale Üniversitesi'nde öğrenim gören 20-30 yaş arası bireyler arasında çalışmanın dahil olma kriterlerini karşılayan gönüllülerin katılımı ile gerçekleştirildi. Gönüllülerin hepsi çalışma hakkında bilgilendirildi ve yazılı olarak onamları alındı. Bu çalışma 1964 yılında yayımlanan ve 2013 yılında revize edilen Helsinki Deklarasyonu ilkelerine uygun şekilde gerçekleştirildi.

\subsubsection{Dahil Edilme ve Hariç Tutulma Kriterleri}

Akıllı telefon sahibi olan, telefonun mesajlaşma, sosyal medya, oyun gibi farklı özelliklerini kullanabilen bireyler dahil edildi. Yürümeyi ve/veya telefonun dokunmatik ekranını kullanmasını gerektiren görevleri yapmayı etkileyebilecek bilinen nörolojik ve/veya ortopedik problemi olanlar çalışma diş1 bırakıldı.

Araştırmaya dahil edilme kriterlerine göre 82 kişi davet edildi. 19 kişi değerlendirmeleri tamamlamadı. Çalışma 20-30 yaş arası 53 bireyin (31 kadın, 22 erkek) katılımıyla tamamlandı.

\subsection{Değerlendirme Yöntemleri}

Katılımciların demografik bilgileri alındıktan sonra yürümenin spatio-temporal karakteristikleri BTS G-Walk Yürüme Analiz Sistemi ile değerlendirildi.

\subsubsection{Yürümenin Değerlendirilmesi}

BTS G-Walk Yürüme Analiz Sistemi kullanılarak hastanın L5-S1 seviyesine takılan analiz portu ile sonuçlar bluetooth aracılığıyla bilgisayara aktarılmaktadır. Analiz sonucunda yürümenin hız, kadans, adım uzunluğu, duruş ve sallanma fazları gibi spatio-temporal parametrelerinin yanı sira pelvis kinematiğine ait bilgiler de elde edilmektedir (Unal vd., 2021).

20-30 yaş arası yetişkin bir bireyde yürüyüşün spatiotemporal karakteristiklerine ait normatif değerler şu şekildedir: adım uzunluğu 70-80 cm, çift adım uzunluğu 150-165 cm, adım uzunluğunun boy uzunluğuna oranı \%49-50,7, yürüme hızı erkeklerde 1,36 m/sn ve kadınlarda 1,33-1,34 m/sn'dir. Dakikada 60 ve daha az adım sayısı yavaş, 80-90 adım orta ve 120'den fazla adım sayısı ise hızlı yürüme temposunu ifade etmektedir. Yürüyüşün \%60-63'ünü duruş fazı ve \%37-40'1nı sallanma fazı oluşturmaktadır (Gouelle, Mégrot, \& Müller, 2018).

Ölçümler sırasında ilk önce 10 metrelik bir mesafe belirlenerek katılımcılardan kendi belirledikleri tempoda yürümeleri istendi. Daha sonra kendi akıllı telefonlarını kullanarak sırasıyla müzik dinleyerek, metin yazarak, sosyal medyada dolaşarak ve oyun oynayarak aynı mesafeyi yürümeleri istendi.

İkinci ölçüm için müzik dinleme görevi sırasında kendi müzik arşivlerinden kendi belirledikleri müzikleri dinleyerek yürümeleri istendi.

Üçüncü ölçüm için metin yazma görevinde telefonun akıllı, otomatik klavyesi kapalı olacak şekilde "Ben Pamukkale Üniversitesi’nde öğrenciyim.” cümlesini yazmaları istendi.

Dördüncü ölçüm için sosyal medya kullanımı ve beşimci ölçüm için oyun oynama sırasında da katılımcılar telefonlarında yüklü olan ve uygulamasına alışık oldukları programları kullandilar.

\section{3. İstatistiksel Analiz}

Referans çalışmada elde edilen etki büyüklüğünün düşük düzeyde olduğu $\left(\eta p^{2}=0,17\right)$ görüldü (Haga vd. 2015). Referans çalışmadaki sonuçlardan yola çıkarak daha yüksek düzeyde bir etki büyüklüğü de elde edebileceğimizi $\left(\eta p^{2}=0,5\right)$ varsayarak yaptığımız güç analizi sonucunda, çalışmaya en az 50 kişi alındığında \%95 güven düzeyinde $\% 90$ güç elde edilebileceği hesaplandı. Veriler SPSS Statistics 21.0 paket programıla analiz edildi. Sürekli değişkenler ortalama \pm standart sapma $(\mathrm{Ort} \pm \mathrm{SS})$ ve kategorik değişkenler de sayı (n) ve yüzde (\%) olarak verildi. Verilerin normal dağılıma uygunlukları Kolmogorov-Smirnov testi ile incelendi. Bağımlı grup karşılaştırmalarında, parametrik test varsayımları sağlandığında Tekrarlı Ölçümlerde Varyans Analizi; parametrik test varsayımları sağlanmadığında ise Friedman Testi kullanıldı. Farklılığ 1 yaratan verileri test etmek için parametrik test varsayımları sağlandığında İki eş arasındaki farkın önemlilik testi; parametrik test varsayımları sağlanmadığında ise Wilcoxon İşaretli Sıra testi uygulandı. İstatistiksel test sonuçlarında anlamlılık düzeyi $\mathrm{p}<0,05$ olarak kabul edildi. 


\section{Araştırma Sonuçları ve Tartışma}

\subsection{Katılımeıların Demografik Özellikleri}

Çalışmaya katılan 53 bireyin yaş ortalaması 23,00土1,60 yıl ve vücut kitle indeksi 22,30 $\pm 3,98 \mathrm{~kg} / \mathrm{m}^{2}$ 'dir. Katılımcıların demografik bilgileri Tablo 1'de verildi.

Tablo 1. Katılımcıların Demografik Özellikleri

\begin{tabular}{|c|c|}
\hline Değişkenler & $\begin{array}{c}\text { Katılımcılar }(n=53) \\
n(\%)\end{array}$ \\
\hline \multicolumn{2}{|l|}{ Cinsiyet } \\
\hline Kadın & $31(58,5)$ \\
\hline \multirow[t]{2}{*}{ Erkek } & $22(41,5)$ \\
\hline & Ort $\pm \mathrm{Ss}$ \\
\hline Yaş (yll) & $23,00 \pm 1,60$ \\
\hline Boy uzunluğu $(\mathrm{cm})$ & $170,79 \pm 9,00$ \\
\hline Vücut ăğlrlı̆̆l (kg) & $65,69 \pm 16,25$ \\
\hline Vücut kitle indeksi $\left(\mathrm{kg} / \mathrm{m}^{2}\right)$ & $22,30 \pm 3,98$ \\
\hline
\end{tabular}

Ort: Ortalama, Ss: Standart sapma

\subsection{Katılımcıların Yürüme Karakteristikleri}

Yapılan ilk değerlendirmede yürüme hızı ortalaması $1,32 \pm 0,19 \mathrm{~m} / \mathrm{sn}$, kadans $111,57 \pm 15,23 \mathrm{ad} / \mathrm{m} / \mathrm{dk}$ ve yürüme döngüsü simetrisi \%96,61 olarak bulundu.

Yürüme sırasında cep telefonu kullanımı nedeniyle yürüyüşün hızı, kadansı, sağ ve sol çift adım uzunluğu, sağ ve sol duruş fazı, sağ ve sol sallanma fazı ve pelvik rotasyon simetrisinde istatistiksel olarak anlamlı farklılıklar tespit edildi $(\mathrm{p}<0,05)$.

Yürüme hızı ve kadansının en fazla azaldığı, çift adım uzunluğunun kısaldığı ve pelvik rotasyon simetrisinin en çok bozulduğu görevin metin yazarak yürüme olduğu görüldü. Bununla birlikte müzik dinleyerek yürüme sonucunda sağ ve sol duruş fazında kısalma, sağ yürüme kalitesi ve pelvik tilt simetrisinde azalma tespit edildi. Yürümenin spatio-temporal parametreleri Tablo 2'de detaylı olarak gösterildi.

Tablo 2. Yürümenin Spatio-temporal Karakteristikleri

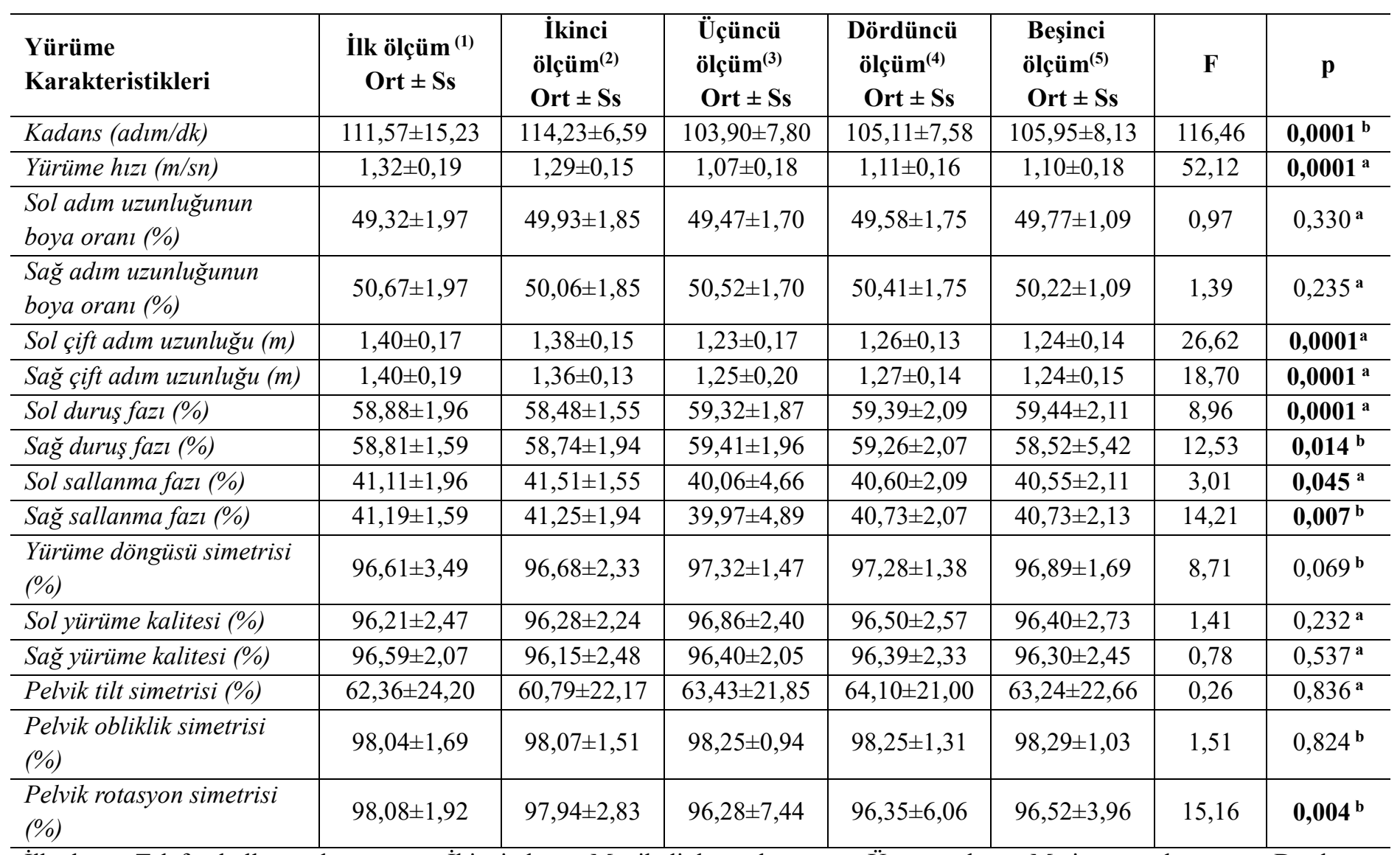

İlk ölçüm: Telefon kullanmadan yürüme, İkinci ölçüm: Müzik dinleyerek yürüme, Üçüncü ölçüm: Metin yazarak yürüme, Dördüncü ölçüm: Sosyal medyada dolaşarak yürüme, Beşinci ölçüm: Oyun oynayarak yürüme, ${ }^{\text {a }}$ Tekrarlı Ölçümlerde Varyans Analizi,

${ }^{\mathrm{b}}$ Friedman Testi 


\subsection{Telefon Kullanarak Yürüme Sırasındaki Spatio-temporal Karakteristiklerin Karşılaştırılması}

Yürüme sırasında telefon kullanımının yürümenin bazı spatio-temporal karakteristiklerini değiştirdiği görüldü. Müzik dinleyerek yürüme sırasında sadece yürüme kadansında artış $(\mathrm{p}=0,0001)$ gözlenirken, metin yazarak yürüme sırasında kadans, hız, çift adım uzunluğu, duruş ve sallanma fazları ve pelvik rotasyon simetrisinin değiştiği görüldü $(p<0,05)$. Yürürken sosyal medyada dolaşmanın yürümenin kadansı, hızı, çift adım uzunluğu, sağ-sol duruş fazı, sağ sallanma fazı ve pelvik rotasyon simetrisini değiştirdiği saptand $1 \quad(p<0,05)$. Oyun oynarken yürümenin hız, kadans, çift adım uzunluğu, sol sallanma fazı ve pelvik rotasyon simetrisini azalttığı tespit edildi $(\mathrm{p}<0,05)$. Cep telefonu kullanarak yürüme sırasında spatio-temporal yürüme karakteristiklerindeki oluşan farklılıklar Tablo 3'te detaylı olarak verildi.

Tablo 3. Cep Telefonu Kullanarak Yürüme Strasında Spatio-Temporal Yürüme Karakteristiklerindeki Değişim

\begin{tabular}{l|c|c|c|c|c|c|c|c|c|c}
\hline $\begin{array}{l}\text { Yürüme } \\
\text { Karakteristikleri }\end{array}$ & $\mathbf{p}^{1-2}$ & $\mathbf{p}^{1-3}$ & $\mathbf{p}^{1-4}$ & $\mathbf{p}^{\mathbf{1 - 5}}$ & $\mathbf{p}^{2-3}$ & $\mathbf{p}^{2-4}$ & $\mathbf{p}^{2-5}$ & $\mathbf{p}^{3-4}$ & $\mathbf{p}^{3-5}$ & $\mathbf{p}^{4-5}$ \\
\hline Kadans (adım/dk) & $\mathbf{0 , 0 0 0 1}$ & $\mathbf{0 , 0 0 0 1}$ & $\mathbf{0 , 0 0 0 1}$ & $\mathbf{0 , 0 0 0 1}$ & $\mathbf{0 , 0 0 0 1}$ & $\mathbf{0 , 0 0 0 1}$ & $\mathbf{0 , 0 0 0 1}$ & 0,076 & $\mathbf{0 , 0 1 0}$ & 0,234 \\
\hline Yürüme hizı $(m /$ sn) & 0,402 & $\mathbf{0 , 0 0 0 1}$ & $\mathbf{0 , 0 0 0 1}$ & $\mathbf{0 , 0 0 0 1}$ & $\mathbf{0 , 0 0 0 1}$ & $\mathbf{0 , 0 0 0 1}$ & $\mathbf{0 , 0 0 0 1}$ & 0,085 & 0,127 & 0,634 \\
\hline Sol çift adım uzunluğu (m) & 0,465 & $\mathbf{0 , 0 0 0 1}$ & $\mathbf{0 , 0 0 0 1}$ & $\mathbf{0 , 0 0 0 1}$ & $\mathbf{0 , 0 0 0 1}$ & $\mathbf{0 , 0 0 0 1}$ & $\mathbf{0 , 0 0 0 1}$ & 0,099 & 0,454 & 0,274 \\
\hline Sağ çift adım uzunluğu $(m)$ & 0,950 & $\mathbf{0 , 0 0 0 1}$ & $\mathbf{0 , 0 0 0 1}$ & $\mathbf{0 , 0 0 0 1}$ & $\mathbf{0 , 0 0 0 1}$ & $\mathbf{0 , 0 0 0 1}$ & $\mathbf{0 , 0 0 0 1}$ & 0,333 & 0,858 & 0,335 \\
\hline Sol duruş fazı (\%) & 0,317 & $\mathbf{0 , 0 0 4}$ & $\mathbf{0 , 0 0 5}$ & $\mathbf{0 , 0 0 4}$ & $\mathbf{0 , 0 0 0 1}$ & $\mathbf{0 , 0 0 0 1}$ & $\mathbf{0 , 0 0 0 1}$ & 0,911 & 0,753 & 0,667 \\
\hline Săg duruş fazı (\%) & 0,908 & $\mathbf{0 , 0 0 3}$ & $\mathbf{0 , 0 3 7}$ & 0,143 & $\mathbf{0 , 0 0 4}$ & 0,119 & 0,075 & 0,400 & 0,394 & 0,866 \\
\hline Sol sallanma fazı (\%) & 0,317 & $\mathbf{0 , 0 4 4}$ & 0,551 & $\mathbf{0 , 0 0 4}$ & $\mathbf{0 , 0 1 7}$ & 0,288 & $\mathbf{0 , 0 0 0 1}$ & 0,176 & 0,433 & 0,268 \\
\hline Săg sallanma fazı (\%) & 0,944 & $\mathbf{0 , 0 0 3}$ & $\mathbf{0 , 0 1 2}$ & 0,077 & $\mathbf{0 , 0 0 4}$ & 0,063 & $\mathbf{0 , 0 3 9}$ & 0,521 & 0,463 & 0,920 \\
\hline $\begin{array}{l}\text { Pelvik rotasyon simetrisi } \\
\text { (\%) }\end{array}$ & 0,101 & $\mathbf{0 , 0 0 0 1}$ & $\mathbf{0 , 0 0 5}$ & $\mathbf{0 , 0 0 1}$ & $\mathbf{0 , 0 4 2}$ & 0,121 & $\mathbf{0 , 0 1 1}$ & 0,633 & 0,580 & 0,204 \\
\hline
\end{tabular}

${ }^{1}$ Telefon kullanmadan yürüme, ${ }^{2}$ Müzik dinleyerek yürüme, ${ }^{3}$ Metin yazarak yürüme, ${ }^{4}$ Sosyal medyada dolaşarak yürüme,

${ }^{5}$ Oyun oynayarak yürüme

Goddard ve ark. (2018) yaş ortalaması 21 yıl olan 15 sağlıklı bireyin metin yazarken yürüme parametrelerindeki değişimi inceledikleri çalışmalarında postüral salınımın arttığını ve adım uzunluğu, çift adım uzunluğu ve yürüme hızında belirgin azalma olduğunu tespit etmişlerdir. Onefroi ve ark. (2020) genç yetişkin 35 bireyin katıldığ çalıșmalarında yürürken telefonla konuşma ve mesajlaşmanın postüral kontrolü bozarak yürüme simetrisini azalttığını bildirmişlerdir.

Benzer şekilde Crowley, Madeleine \& Vuillerme'nin (2019) çalışmalarında 10 genç yetişkin bireyden normal yürüme temposunda ve hızlı yürüme temposunda istenilen metni yazarak yürümelerini istenmiştir. Elde ettikleri sonuçlara göre her iki yürüme temposunda da metin yazarak yürümenin, telefon kullanmadan yürüme sırasında elde edilen parametrelerden daha bozuk olduğunu belirtmişlerdir. Bizim sonuçlarımız da metin yazarak yürüme sırasında kadans, hız, çift adım uzunluğu, duruş ve sallanma fazları ve pelvik rotasyon simetrisinin azaldığını göstermiştir.

Yürüme hızı düşmenin önemli bir belirleyicisidir. Yürürken cep telefonuyla ilgilenmek yürüme hızında azalmaya neden olarak kişiyi düşmelere karşı açık hale getirir (Hollman vd., 2007; Moyer vd., 2006). Nasar ve Troyer (2013) toplum içinde mobilitesini sağlarken cep telefonu kullanan yayaların düşme sıklığının daha fazla olduğunu ve sürücü kaynaklı trafik kazalarından sonra en çok telefon kullanarak trafikte dolaşan yayalardan kaynaklı yaralanmalar ortaya çıktığını bildirmişlerdir.
Laatar ve ark. (2017) gençlerde ve yaşlilarda telefon kullanımın postüral stabilite ve mobilite üzerine etkilerini araştırdıkları çalışmalarında telefonla konuşma, birini arama ve müzik dinleme görevleri sırasında hem gençlerde hem de yaşlı bireylerde telefon kullanımı sırasında postüral stabilitenin bozulduğunu ve yürüme hızının düştüğünü bildirmişlerdir. Bizim sonuçlarımız da müzik dinleyerek yürüme sırasında yürümenin hızında anlamlı düzeyde azalma olduğunu göstermiştir.

\section{Sonuç}

Yürüme sırasında cep telefonu kullanımı hız, kadans, adım uzunluğu, duruş ve sallanma fazları gibi spatio-temporal özelliklerini bozmaktadır. Günlük işler sırasında cep telefonu kullanımının artması yapılan işe odaklanmayı ve konsantrasyonu azaltmaktadır. Telefon kullanımı nedeniyle yürüme parametrelerinde ortaya çıkan bozulmalar, kazalar veya yaralanmalara yol açabilmektedir. Dolayısıyla günlük yaşam sırasında sıkça yaptığımız yürüme aktivitelerini güvenli bir ortamda yapabilmek için cep telefonu kullanımı gibi dikkati dağıtacak durumlardan kaçınılmasını öneriyoruz.

\section{Teșekkür}

Araştırmacılar çalışmaya dahil olan tüm bireylere katkılarından dolayı teşekkür etmektedirler. 


\section{Kaynakça}

Crowley, P., Madeleine, P., \& Vuillerme, N. (2019). The effects of mobile phone use on walking: a dual task study. $B M C$ Research Notes, 12(1), 1-6.

Goddard, E. C., Remler, P. T., Roos, R. H., \& Turchyn, R. (2018). The Effect of Texting on Balance and Temporospatial Aspects of Gait. Western Undergraduate Research Journal: Health and Natural Sciences, 9(1).

Gouelle, A., Mégrot, F., \& Müller, B. (2018). Interpreting spatiotemporal parameters, symmetry, and variability in clinical gait analysis. Handbook of Human Motion, eds. B. Müller, SI Wolf, GP Brueggemann, Z. Deng, A. McIntosh, F. Miller, and WS Selbie (Cham: Springer International Publishing), 689-707.

Haga, S., Sano, A., Sekine, Y., Sato, H., Yamaguchi, S., \& Masuda, K. (2015). Effects of using a smart phone on pedestrians' attention and walking. Procedia Manufacturing, 3, 2574-2580.

Hollman, J. H., Kovash, F. M., Kubik, J. J., \& Linbo, R. A. (2007). Age-related differences in spatiotemporal markers of gait stability during dual task walking. Gait \& Posture, 26(1), 113-119.

Laatar, R., Kachouri, H., Borji, R., Rebai, H., \& Sahli, S. (2017). The effect of cell phone use on postural balance and mobility in older compared to young adults. Physiology \& Behavior, 173, 293-297.

Moyer, B. E., Chambers, A. J., Redfern, M. S., \& Cham, R. (2006). Gait parameters as predictors of slip severity in younger and older adults. Ergonomics, 49(4), 329-343.

Mustafaoglu, R., Yasaci, Z., Zirek, E., Griffiths, M. D., \& Ozdincler, A. R. (2021). The relationship between smartphone addiction and musculoskeletal pain prevalence among young population: a cross-sectional study. The Korean Journal of Pain, 34(1), 72.

Nasar, J. L., \& Troyer, D. (2013). Pedestrian injuries due to mobile phone use in public places. Accident Analysis \& Prevention, 57, 91-95.

Oliver, B., \& Goerke, V. (2007). Australian undergraduates' use and ownership of emerging technologies: Implications and opportunities for creating engaging learning experiences for the Net Generation. Australasian Journal of Educational Technology, 23(2).

Onofrei, R. R., Amaricai, E., Suciu, O., David, V. L., Rata, A. L., $\&$ Hogea, E. (2020). Smartphone use and postural balance in healthy young adults. International Journal of Environmental Research and Public Health, 17(9), 3307.

Unal, A., Altug, F., Tikac, G., \& Cavlak, U. (2021). Effectiveness of matrix-rhythm therapy on increased muscle tone, balance and gait parameters in stroke survivors: a single-blinded, randomized, controlled clinical trial. Acta Neurologica Belgica, 121(3), 689-699.

Yang, X., Yip, B. H., LEE, K. P. E., Zhang, D. D., \& Wong, S. Y. S. (2021). The relationship between technology use and problem technology use and potential psychosocial mechanisms: Population-based telephone survey in community adults during COVID-19. Frontiers in Psychology, 12, 2487.

Yen, C. F., Tang, T. C., Yen, J. Y., Lin, H. C., Huang, C. F., Liu, S. C., \& Ko, C. H. (2009). Symptoms of problematic cellular phone use, functional impairment and its association with depression among adolescents in Southern Taiwan. Journal of Adolescence, 32(4), 863-873. 